Word Count for Manuscript: 2,851

Word Count for Abstract: 249

\title{
PTSD and Risk of Incident Cardiovascular Disease in Aging Veterans
}

\author{
Matthew H. Beristianos, $\mathrm{MA}^{1,2,3}$ \\ Kristine Yaffe, MD, ${ }^{1,2,4}$ Beth Cohen, MD, MAS, ${ }^{2,5}$ \\ Amy L. Byers, PhD, MPH, ${ }^{1,2}$ \\ ${ }^{1}$ Department of Psychiatry, University of California, San Francisco \\ ${ }^{2}$ San Francisco Veterans Affairs Medical Center, San Francisco, CA \\ ${ }^{3}$ Alliant International University, San Francisco, CA \\ ${ }^{4}$ Departments of Neurology and Epidemiology and Biostatistics, \\ University of California, San Francisco \\ ${ }^{5}$ Department of Medicine, University of California, San Francisco
}

Corresponding Author/Author for Reprints: Matthew H. Beristianos, MA, Department of

Psychiatry, University of California, San Francisco, San Francisco VA Medical Center, 4150

Clement Street (116H), San Francisco, CA 94121

Phone: (415) 221-4810 x5836 Fax: (415) 379-5624 E-mail: Matthew.Beristianos@ucsf.edu 
Previous Presentation: Portions of the manuscript were presented at the American Psychological Association (APA) Annual Conference, August, 2013; Honolulu, Hawaii. In addition, portions of the manuscript were presented at the American Association for Geriatric Psychiatry (AAGP) Annual Meeting, March, 2014; Orlando, Florida.

\section{ACKNOWLEDGMENTS}

Study funding: This study was funded by US Department of Defense grant W81XWH-11-20189 (principal investigator: Dr. Byers). Dr. Yaffe is supported in part by a K24 Midcareer Investigator Award from the National Institute on Aging (AG031155). Dr. Cohen is supported in part by the National Heart, Lung, and Blood Institute grant K23 HL 094765-0 and a grant from the American Heart Association.

Author Contributions: Mr. Beristianos had full access to all the data in the study. He conducted the data analysis, and takes responsibility for the integrity of the data and the accuracy of the statistical results. 
Disclaimer: We acknowledge that the original collector of the data, sponsoring organizations, agencies, or the U.S. government bear no responsibility for use of the data or for interpretations or inferences based upon such uses. The views and opinions expressed in this report are those of the authors and should not be construed otherwise. 


\section{ABSTRACT}

Objectives: To determine if late-life PTSD is associated with cardiovascular disease in a sample of older veterans, and if this association is explained above and beyond medical and psychiatric comorbidities. Design: Retrospective cohort study conducted using the Department of Veterans Affairs (VA) National Patient Care Database (2000-2011). Setting: VA medical centers in the United States. Participants: A total of 138,341 veterans 55 years and older without cardiovascular disease at study baseline (2000-2003). Measurements: PTSD and cardiovascular disease (as defined by diagnoses of: cerebrovascular disease [CVD], congestive heart failure $[\mathrm{CHF}]$, myocardial infarction $[\mathrm{MI}]$, and peripheral vascular disease [PVD]) were identified by ICD-9 codes during study baseline (2000-2003) and follow-up (2004-2011), respectively.

Results: Three percent of veterans $(n=4,041)$ had a baseline diagnosis of PTSD. Unadjusted increased risk of incidence of CVD was $80 \%$, CHF was $56 \%$, MI was $82 \%$, and PVD was $60 \%$ in veterans with PTSD compared with those without PTSD. After adjustment for demographics, medical, substance use, and psychiatric comorbidities, veterans with late-life PTSD were at a $45 \%$ increased risk for incident CVD, $26 \%$ increased risk for incident CHF, $49 \%$ increased risk for incident MI, and 35\% increased risk for PVD compared to veterans without late-life PTSD. Conclusions: Findings highlight the longitudinal impact of PTSD on increasing the incidence of cardiovascular disease in older adults. This study implies the need for greater monitoring and treatment of PTSD in older persons, particularly older veterans, to assist in preventing adverse outcomes, such as cardiovascular disease, over the long term. 


\section{INTRODUCTION}

Posttraumatic Stress Disorder (PTSD) is a common psychiatric diagnosis that is associated with deleterious outcomes, such as increased mortality and a variety of chronic physical health problems. In the general population, lifetime PTSD prevalence rates are between $1.3-7.8 \% .^{1,2}$ It is the most commonly diagnosed mental health disorder in veterans returning from Iraq and Afghanistan, ${ }^{3,4}$ and PTSD rates in men and women serving in Operation Enduring Freedom $(\mathrm{OEF})$ and Operation Iraqi Freedom (OIF) have been found to be as high as $17 \% .^{3}$ In fact, many veterans continue to suffer from PTSD decades after service and into late-life. For example, in studies of Vietnam veterans, $10 \%$ to $15 \%$ still meet criteria for PTSD more than 15 years after discharge. ${ }^{5,6}$ Additionally, World War II and Korean veterans have a PTSD prevalence rate up to $12 \% 45$ years after combat. ${ }^{7}$ With high rates of PTSD being prevalent throughout the lifespan, it is important to understand the impact late-life PTSD has in the aging population.

PTSD has been found to be associated with both an increased risk of medical illness, and with

greater use of health care services. ${ }^{8-12}$ Cardiovascular disease, in particular, has been consistently associated with PTSD, with cerebrovascular disease (CVD), congestive heart failure (CHF), and myocardial infarction (MI) being specific cardiovascular outcomes that have been examined in civilians, ${ }^{13,14}$ veterans, ${ }^{15-19}$ and POWs. ${ }^{20,21}$ However, there is little to no information on the relationship between PTSD and another aspect of cardiovascular disease, peripheral vascular disease (PVD). In addition, of the studies that have examined cardiovascular outcomes, most have been under powered to simultaneously adjust for medical, psychiatric, and substance use comorbidities-which questions whether the association can be accounted for by comorbidities. 
The goal of our study was to determine whether PTSD is associated with increased risk of incident CVD, CHF, MI and PVD diagnoses in a sample of older U.S. veterans. We were additionally interested in whether such associations were explained by comorbid medical, psychiatric and substance use disorders. 


\section{METHODS}

\section{Data and Participants}

Data for this retrospective cohort study were obtained from the VA National Patient Care Database (NPCD), which captures all inpatient and outpatient services within the VA each fiscal year (October 1 through September 30). We utilized a random sample of 200,000 veterans aged 55 years or older who had been treated at a VA health care facility fiscal years 2000 through 2003 (study baseline period), and had at least one follow-up visit between fiscal years 2004 through 2011. We excluded veterans with a diagnosis of CVD, CHF, MI or PVD during the baseline period. This resulted in a final sample of 138,341. Although the final study sample was similar on demographics and psychiatric disorders to those veterans who had baseline vascular disease and were excluded from the study, veterans excluded had higher baseline medical comorbidities (e.g., hypertension, diabetes, and chronic pulmonary disease).

The Committee on Human Research at the University of California, San Francisco, the Committee for Research and Development at the San Francisco VA and the Human Research Protection Office of the U.S. Army Medical Research and Materiel Command approved the study.

\section{Measures}

Predictor: Posttraumatic Stress Disorder

Veterans with PTSD were identified using International Classification of Diseases, Ninth Revision, Clinical Modification (ICD-9-CM) codes recorded in the VA database. To be 
conservative, only those with a diagnosis code of 309.81 (PTSD) on at least two different visits during the baseline period were classified as having PTSD.

\section{Outcome: Cardiovascular Disease}

Veterans with cardiovascular disease were identified using ICD-9 diagnoses recorded in the VA database. The vascular disorders of interest for the present study were: cerebrovascular disease (430-438), congestive heart failure (428), myocardial infarction $(410,412)$, and peripheral vascular disease $(441,443.9)$. These codes were applied during the baseline period to exclude prevalent cases and during the follow-up period to identify incident cases. If cardiovascular disease was not diagnosed before the veteran's death or the end of the follow-up period, the veteran's data was censored at whichever event occurred first.

\section{Covariates}

\section{Demographic Variables}

We obtained data on age and gender from the VA database. We estimated education level and income based on Census Data. Veterans were classified as living in educational and income strata according to zip code tabulation areas by linking our data to 2000 U.S. Census data. ${ }^{22}$ For educational level, veterans were categorized according to whether they were living in a zip code tabulation area (ZCTA) where $25 \%$ or less versus greater than $25 \%$ of the adult population had completed a college education (bachelor's degree or higher). For income, veterans were categorized by tertiles of median ZCTA income for adults $<75$ or $\geq 75$ years old. This same methodology has been used in previously published research of veterans. ${ }^{23,24}$ 
Medical, Psychiatric and Substance Use Comorbidities

All medical, substance use, and psychiatric comorbidities were based on current VHA coding guidelines, ${ }^{25}$ and identified by ICD-9 codes during the baseline period. Medical comorbidities assessed as potential confounders included traumatic brain injury (TBI), dementia, renal disease, hypertension, diabetes, chronic pulmonary disease, and cancer. Psychiatric comorbidities included diagnoses of depression, bipolar disorder, generalized anxiety disorder, panic disorder, phobic disorder, substance abuse, alcohol abuse, and tobacco dependence.

\section{Statistical Analyses}

Baseline characteristics were summarized comparing veterans with PTSD versus without PTSD. The statistical significance of differences between the two groups was tested by t-tests for continuous variables and $\chi^{2}$ tests for categorical variables.

Cox proportional hazard models were used to compare the age of incident cardiovascular diagnoses in patients with and without PTSD. Hazard ratios were estimated for the association between baseline PTSD and cardiovascular diagnosis. To determine whether the association was influenced by medical comorbidities, substance use disorders, and psychiatric disorders, we constructed several models that included these potential confounders. First, we examined the association of PTSD and cardiovascular disease adjusting for demographic variables (i.e., sex, education, and income) and then we examined the association adjusting separately for medical comorbidities (i.e., dementia, TBI, renal disease, hypertension, diabetes, cancer, and chronic pulmonary disease), and psychiatric and substance use disorders. Finally, we created a model adjusting for all of these covariates simultaneously. 
Proportional hazards assumptions were evaluated graphically and statistically and determined to be satisfied for all models. Statistical tests for models were two-tailed with $p<0.05$ defining statistical significance. All analyses were performed using SAS version 9.3 (SAS Institute Inc, Cary, North Carolina). 


\section{RESULTS}

The baseline demographic characteristics of the 138,341 veterans are presented in Table 1 . The mean age was 67.8 years (SD 8.1) and $4.1 \%$ were female. Three percent of the sample $(n=$ 4,041) had a current (i.e., during the baseline period) diagnosis of PTSD. Compared to veterans without PTSD, those with PTSD were significantly younger, and were more likely to live in an area with higher income individuals. For the majority of comorbidities, veterans with PTSD had a significantly higher prevalence of medical, psychiatric, and substance use disorders than veterans without PTSD. Absolute differences in medical comorbidities were generally small. However, larger absolute differences were seen in the prevalence rates of psychiatric and substance use disorders, such as depression, drug abuse/dependence, alcohol abuse/dependence, and tobacco dependence.

\section{Risk of Incident Cardiovascular Disease}

Eight-year cumulative incidence rates for all four outcomes (CVD, CHF, MI, and PVD) were significantly higher for veterans with PTSD than those without PTSD. Veterans with PTSD had a CVD cumulative incidence rate of $16.1 \%$, while those without PTSD had a rate of $12.0 \%$. Similar results were found for CHF (i.e., $11.6 \%$ vs $10.0 \%)$ and PVD (12.8\% and 10.7\%). Furthermore, veterans with PTSD had an 8-year MI cumulative incident rate of 8.0\%, while it was $5.7 \%$ for those without PTSD. In addition, rates of incident cardiovascular disease were higher for veterans with PTSD than those without PTSD throughout the follow-up period (Figures 1-4). 
Hazard ratios (HR) based on Cox proportional hazards models using age as the timescale showed significant increase in the risk of incident diagnosis for CVD, CHF, MI, and PVD (Table 2). Unadjusted and demographically-adjusted models showed similar significant findings, where the risk of incident CVD and MI was almost 2-fold higher for veterans with PTSD compared to those without PTSD, and the risk for CHF and PVD is 60\% higher in veterans with PTSD. With adjustment for medical comorbidities and substance use disorders, the results were slightly attenuated. However, upon adjustment for psychiatric disorders the results for all vascular outcomes were attenuated though still significant, resembling the final fully-adjusted model. In the final fully-adjusted model, including demographic variables, medical comorbidities, substance use disorders, and psychiatric disorders, veterans with late-life PTSD were at a 45\% increased risk for incident cerebrovascular disorder and $49 \%$ increased risk for myocardial infarction over 8 years, while they were at a $26 \%$ increased risk for incident congestive heart failure and 35\% increased risk for peripheral vascular disease, compared to veterans without PTSD.

In sensitivity analyses, we examined veterans with a diagnosis of PTSD at 1 or more visits in order to assess potential differences in the associations compared to our more conservative PTSD definition of at least 2 diagnoses. We found that the magnitude and statistical significance of the HR's for all cardiovascular outcomes remained similar to the original models. Furthermore, to assess whether increased health visits associated with PTSD could provide additional opportunities for a cardiovascular diagnosis, we ran a sensitivity analysis with average number of inpatient and outpatient visits per month included in the final models. The results were slightly attenuated, but, in general, remained similar to the original models. 


\section{DISCUSSION}

In this study of older veterans, we found that veterans diagnosed with PTSD had a 45-49\% increased risk of cerebrovascular disease and myocardial infarction and a 26-35\% increased risk of congestive heart failure and peripheral vascular disease later in life compared with veterans without PTSD independent of sociodemographics, medical, substance use, and psychiatric disorders. Compared to those with no PTSD, risk of cardiovascular disease remained high regardless of age.

Although a significant relationship has been found between PTSD and cardiovascular disease, our study expands upon previous work by focusing on older adults, utilizing a large VA dataset, studying a spectrum of cardiovascular outcomes and accounting for multiple medical, substance use and psychiatric comorbidities, and including almost 10 years of follow-up data. Interestingly, the present study found an almost 50\% increased risk for incident MI while previous studies have found $25-26 \%$ increased MI risk in veterans. ${ }^{17,18}$ Although our study found a higher risk, it is difficult to compare the magnitude of increased risk across studies due to variations in the study populations and designs. Our results indicating that older veterans with PTSD were $45 \%$ more likely to develop incident CVD are similar to a study examining individuals exposed to 9/11 who had PTSD at study enrollment, where the authors found that these individuals were $53 \%$ more likely to be hospitalized for CVD. ${ }^{13}$ Furthermore, in a study examining cardiovascular outcomes in WWII POWs with PTSD, the authors found a 58\% higher likelihood of circulatory diseases and a $25 \%$ higher likelihood of hypertension when compared with POWs without PTSD. ${ }^{21}$ This study had an older sample similar to ours, but was crosssectional. Also of note is the comparison of our findings of the association between PTSD and 
CHF to a meta-analysis examining the same relationship. ${ }^{22}$ Our findings reflect a similar attenuation when adjusting for depression where their aggregate HR following adjustment for depression was 1.27 , and our HR is 1.35 with adjustment for depression as well as other psychiatric disorders. Though the confidence intervals for our associations of PTSD and the various cardiovascular diagnoses overlap, the point estimates for each condition were somewhat different, with cerebrovascular disease and myocardial infarction being greater than congestive heart failure and peripheral vascular disease. It is not possible from our data to determine why these point estimates differ, and indeed these conditions have similar risk factors and are often comorbid in the same individuals. ${ }^{23-25}$

To our knowledge, our study represents the first findings on the relationship between late-life PTSD and peripheral vascular disease, where veterans with late-life PTSD were $35 \%$ more likely to develop PVD in the fully-adjusted model. Results from a recent systematic review estimate that in 2010 over 200 million people worldwide were living with PVD. ${ }^{26}$ The authors also found that the prevalence of PVD had increased substantially from 2000 to 2010 in low, middle, and high income countries. Patients with PVD experience painful symptoms, limited functional status, and a nearly three-fold increase in risk of stroke or myocardial infarction. Given the substantial morbidity and financial cost associated with PVD, it is very important for the VA and other healthcare systems to examine PVD prevalence and risk factors in their aging patient populations.

While other studies examining the relationship between PTSD and cardiovascular disease have studied samples including both young and older individuals, our study specifically targeted older 
veterans. This is particularly important to emphasize due to recent literature indicating the detrimental effect PTSD can have in late life. PTSD in late-life has been shown to be associated with cognitive impairment, ${ }^{31}$ an increased risk of developing dementia, ${ }^{29}$ and an increased risk of disability. ${ }^{28}$ Our results add to this growing literature. We specifically studied older veterans who were 55 years or older who did not have any of the four cardiovascular diagnostic outcomes during the baseline period. Thus, we are able to state that a diagnosis of PTSD is significantly associated with increased risk of incident cardiovascular disease in late life. Although most attention is paid to veterans newly returned from the war zone, our findings suggest that it is crucial to study how PTSD unfolds and manifests itself with age; thus, younger veterans will benefit from current examinations of psychological afflictions in older veterans.

Several mechanisms have been theorized explaining the relationship between PTSD and cardiovascular disease. Biologically, PTSD and cardiovascular dysfunction have been related to the dysregulation of the hypothalamic-pituitary-adrenal (HPA) axis, ${ }^{33}$ and alterations to pathways in the autonomic nervous system caused by PTSD symptoms have also been implicated in the development of vascular problems such as high blood pressure and blood coagulation. ${ }^{34,35}$ Many behavioral risk factors for cardiovascular disease in those with PTSD have been proposed as well, with studies showing that persons with PTSD have more difficulty with tobacco cessation, ${ }^{36}$ have an increased risk of obesity, ${ }^{37,38}$ and are less physically active. ${ }^{39,40}$ Finally, there are several psychosocial risk factors that are likely involved in the relationship between PTSD and cardiovascular disease, including low social support ${ }^{41}$ and socioeconomic status. ${ }^{42}$ 
The present study has several important strengths. It is the first study, to our knowledge, that has assessed multiple cardiovascular outcomes in individuals with PTSD. In addition, our study had the power to adjust for multiple psychiatric, substance use, and medical comorbidities that are often present in older adults and those with PTSD. In fact, it is possible, but difficult to know the exact temporality from this data, that some of the covariates may be in the causal pathway between PTSD and cardiovascular disease. In this case, our findings would be an underestimation of the association between PTSD and cardiovascular disease. Our study findings additionally provide evidence supporting the ever-expanding literature on the adverse physical health outcomes associated with PTSD. Finally, this study is also unique in that it examined this relationship longitudinally, over 8 years.

Limitations include a veteran sample that was predominately male; thus, making it difficult to generalize findings to civilians and women. Additionally, information biases are important to consider in this study. First, all diagnoses were based on ICD-9-CM codes, which are an insensitive assessment of symptoms when compared to structured research diagnostic interviews. Second, the validity of the diagnoses could not be confirmed. However, in an effort to be conservative about PTSD diagnoses, we only included veterans in the PTSD group who had at least two visits at the VA with a PTSD diagnosis. Despite this, we could not assess accurately chronicity of PTSD, which would be an important area for future research. Third, it is possible that those veterans with PTSD had increased likelihood of health visits associated with PTSD that provided additional opportunities for diagnosis of CVD. However, to address this possibility, we adjusted for number of inpatient and outpatient visits in the final model. Finally, limitations of utilizing this VA administrative dataset included the availability of data until 
FY2011 and not beyond, and inability to monitor receipt of care outside the VA during the study period.

The results of the present study reveal several clinical implications for those who work with older veterans with PTSD, and emphasize the importance of monitoring patients with PTSD for the development of cardiovascular disease as they age. Further research is needed to ascertain whether treatment for PTSD can reduce risk for cardiovascular disease. In addition, research in civilians and women is needed to determine if the current results are applicable to these populations. Finally, understanding mechanisms for this relationship will allow for better targeting of interventions. With such a dramatic rise of older adults anticipated in the population, and with veterans of more recent war conflicts reaching older age, it is essential that the diagnosis and successful treatment of PTSD is achieved in order to improve the health and outcomes of elders in late life. 


\section{REFERENCES}

1. Davidson JR, Stein DJ, Shalev AY, et al: Posttraumatic stress disorder: acquisition, recognition, course, and treatment. J Neuropsychiatry Clin Neurosci 2004; 16:135-147

2. Kessler RC, Berglund P, Demler O, et al: Lifetime prevalence and age-of-onset distributions of DSM-IV disorders in the National Comorbidity Survey Replication. Arch Gen Psychiatry $2005 ; 62: 593-602$

3. Hoge CW, Castro CA, Messer SC, et al: Combat duty in Iraq and Afghanistan, mental health problems, and barriers to care. N Engl J Med 2004; 351:13-22

4. Hoge CW, Auchterlonie JL, Milliken CS: Mental health problems, use of mental health services, and attrition from military service after returning from deployment to Iraq or Afghanistan. JAMA 2006; 295:1023-1032

5. Dohrenwend BP, Turner JB, Turse NA, et al: The psychological risks of Vietnam for US veterans: a revisit with new data and methods. Science 2006; 313:979-982

6. Kulka R, Schlenger WE, Fairbank JA, et al: Trauma and the Vietnam War Generation: Report of Findings from the National Vietnam Veterans Readjustment Study. New York, NY, Brunner/Mazel Publishers Inc, 1990.

7. Spiro A, Schnurr PP, Aldwin CM: Combat-related posttraumatic stress disorder symptoms in older men. Psychol Aging 1994; 9:17

8. Boscarino JA: Posttraumatic stress disorder and physical illness: results from clinical and epidemiologic studies. Ann N Y Acad Sci 2004; 1032:141-153 
9. Drescher KD, Rosen CS, Burling TA, et al: Causes of death among male veterans who received residential treatment for PTSD. J Trauma Stress 2003; 16:535-543

10. Hearst N, Newman TB, Hulley SB: Delayed effects of the military draft on mortality. A randomized natural experiment. N Engl J Med 1986; 314:620-624

11. Schnurr PP, Spiro III A, Paris AH: Physician-diagnosed medical disorders in relation to PTSD symptoms in older male military veterans. Health Psychol 2000; 19:91

12. Zatzick DF, Marmar CR, Weiss DS, et al: Posttraumatic stress disorder and functioning and quality of life outcomes in a nationally representative sample of male Vietnam veterans. Am J Psychiatry 1997; 154:1690-1695

13. Jordan, HT, Miller-Archie SA, Cone JE, et al: Heart disease among adults exposed to the September 11, 2001 World Trade Center disaster: Results from the World Trade Center Health Registry. Prev Med 2011; 53:370-376.

14. Kubzansky LD, Koenen KC, Jones C, et al: A prospective study of posttraumatic stress disorder symptoms and coronary heart disease in women. Health Psychol 2009; 28:125-130

15. Boscarino JA: A prospective study of PTSD and early-age heart disease mortality among Vietnam veterans: implications for surveillance and prevention. Psychosom Med 2008; 70:668676

16. Dobie DJ, Kivlahan DR, Maynard C, et al: Posttraumatic stress disorder in female veterans: association with self-reported health problems and functional impairment. Arch Intern Med $2004 ; 164: 394-400$ 
17. Kubzansky LD, Koenen KC, Spiro III A, et al: Prospective study of posttraumatic stress disorder symptoms and coronary heart disease in the normative aging study. Arch Gen Psychiatry 2007; 64:109-116

18. Scherrer JF, Chrusciel T, Zeringue A, et al: Anxiety disorders increase risk for incident myocardial infarction in depressed and nondepressed Veterans Administration patients. Am Heart J 2010; 159:772-779

19. Vaccarino V, Goldberg J, Rooks C, et al: Post-traumatic stress disorder and incidence of coronary heart disease: a twin study. J Am Coll Cardiol 2013; 62:970-978

20. Brass LM, Page WF: Stroke in former prisoners of war. J Stroke Cerebrovasc Dis 1996; $6: 72-78$

21. Kang HK, Bullman TA, Taylor JW: Risk of selected cardiovascular diseases and posttraumatic stress disorder among former World War II prisoners of war. Ann Epidemiol 2006; $16: 381-386$

22. Edmondson D, Kronish IM, Shaffer JA, et al: Posttraumatic stress disorder and risk for coronary heart disease: A meta-analytic review. Am Heart J 2013; 166;806-814

23. Poredos P, \& Jug B: The prevalence of peripheral arterial disease in high risk subjects and coronary or cerebrovascular patients. Angiol 2007; 58:309-315

24. Dieter RS, Tomasson J, Gudjonsson T, et al: Lower extremity peripheral arterial disease in hospitalized patients with coronary artery disease. Vasc Med 2003; 8:233-236 
25. Atmer B, Jogestrand T, Laska J, Peripheral artery disease in patients with coronary artery disease. Int Angiol 1995; 14:89-93

26. Fowkes FGR, Rudan D, Rudan I, et al: Comparison of global estimates of prevalence and risk factors for peripheral artery disease in 2000 and 2010: a systematic review and analysis. Lancet 2013; 382:1329-1340

27. Bauman KJ, Graf NL: Educational attainment: Census 2000 Brief (C2KBR-24). Washington, DC, U.S. Government Printing Office, 2003

28. Byers AL, Covinsky KE, Barnes DE, et al: Dysthymia and depression increase risk of dementia and mortality among older veterans. Am J Geriatr Psychiatry 2012; 20:664-672

29. Yaffe K, Vittinghoff E, Lindquist K, et al: Posttraumatic stress disorder and risk of dementia among US veterans. Arch Gen Psychiatry 2010; 67:608-613

30. United States Department of Veterans Affairs: VA Vital Status Files [description online]. Available at: http://www.virec.research.va.gov/DataSourcesName/VitalStatus/VitalStatus.htm. Accessed January 14, 2010

31. Yehuda R, Tischler L, Golier JA, et al: Longitudinal assessment of cognitive performance in Holocaust survivors with and without PTSD. Biol Psychiatry 2006; 60:714-721

32. Byers AL, Covinsky KE, Neylan TC, et al: Chronicity of posttraumatic stress disorder and disk of disability in older persons. JAMA Psychiatry 2014; 71:540-546

33. Boscarino JA: Post-traumatic stress disorder and cardiovascular disease link: time to identify specific pathways and interventions. Am J Cardiol 2011; 108:1052-1053 
34. Bedi US, Arora R: Cardiovascular manifestations of posttraumatic stress disorder. J Natl Med Assoc 2007; 99:642

35. Brotman DJ, Golden SH, Wittstein IS: The cardiovascular toll of stress. Lancet 2007; $370: 1089-1100$

36. Dedert EA, Calhoun PS, Harper LA, et al: Smoking Withdrawal in Smokers with and without Posttraumatic Stress Disorder. Nicotine Tob Res 2012; 14:372-376

37. Cohen BE, Marmar C, Ren L, et al: Association of cardiovascular risk factors with mental health diagnoses in Iraq and Afghanistan war veterans using VA health care. JAMA 2009; $302: 489-492$

38. Scott KM, McGee MA, Wells JE, et al: Obesity and mental disorders in the adult general population. J Psychosom Res 2008; 64:97-105

39. Buckley TC, Mozley SL, Bedard MA, et al: Preventive health behaviors, health-risk behaviors, physical morbidity, and health-related role functioning impairment in veterans with post-traumatic stress disorder. Mil Med 2004; 169:536-540

40. Zen AL, Whooley MA, Zhao S, et al: Post-traumatic stress disorder is associated with poor health behaviors: findings From the Heart and Soul Study. Health Psychol 2012; 31:194-201

41. Davidson J, Hughes D, Blazer D, et al: Post-traumatic stress disorder in the community: an epidemiological study. Psychol Med 1991; 21:713-721

42. Marmot M: Inequalities in health. N Engl J Med 2001; 345:134-135 


\section{Figure Legend.}

Figure 1. Cumulative Incidence of Cerebrovascular Disorder by Age

Figure 2. Cumulative Incidence of Congestive Heart Failure by Age

Figure 3. Cumulative Incidence of Myocardial Infarction by Age

Figure 4. Cumulative Incidence of Peripheral Vascular Disease by Age 
Table 1. Baseline Characteristics of Older Veterans with PTSD and No PTSD

\begin{tabular}{|c|c|c|c|}
\hline Characteristic & $\begin{array}{c}\text { PTSD } \\
(n=4,041)\end{array}$ & $\begin{array}{c}\text { No PTSD } \\
(\mathrm{n}=\mathbf{1 3 4 , 3 0 0 )}\end{array}$ & $d f, p^{\mathrm{a}}$ \\
\hline Age, y, mean (SD) & $64.4(8.8)$ & $67.9(8.0)$ & $1,<0.001$ \\
\hline Male, $\mathrm{n}(\%)$ & 3,957 (97.9) & $128,607(97.0)$ & $1,<0.001$ \\
\hline \multicolumn{4}{|l|}{ Education of $\mathrm{ZCTA}^{\mathrm{b}}, \mathrm{n}(\%)$} \\
\hline$>25 \%$ college-educated & $1,285(33.4)$ & $41,456(32.0)$ & $1,>0.05$ \\
\hline Income (median) of $\mathrm{ZCTA}^{\mathrm{b}, \mathrm{c}}, \mathrm{n}(\%)$ & & & $2,<0.05$ \\
\hline Low tertile $(<\$ 23.8 \mathrm{~K})$ & $1,199(31.1)$ & $42,762(33.0)$ & \\
\hline Middle tertile & $1,364(35.4)$ & $44,163(34.0)$ & \\
\hline High tertile $(>\$ 31.5 \mathrm{~K})$ & $1,293(33.5)$ & $42,822(33.0)$ & \\
\hline \multicolumn{4}{|l|}{ Medical Comorbidities, n (\%) } \\
\hline Dementia & $187(4.6)$ & $3,308(2.5)$ & $1,<0.001$ \\
\hline Traumatic Brain Injury & $68(1.7)$ & $699(0.5)$ & $1,<0.001$ \\
\hline Renal Disease & $140(3.5)$ & $4,846(3.6)$ & $1,>0.05$ \\
\hline Hypertension & $2,725(67.4)$ & $86,862(64.7)$ & $1,<0.001$ \\
\hline Diabetes & $1,074(26.6)$ & $32,319(24.1)$ & $1,<0.001$ \\
\hline Cancer & $828(20.5)$ & $25,124(18.7)$ & $1,<0.01$ \\
\hline Chronic Pulmonary Disease & $1,190(29.5)$ & $27,748(20.7)$ & $1,<0.001$ \\
\hline \multicolumn{4}{|l|}{ Psychiatric Disorders, n (\%) } \\
\hline Depression & $1,933(47.8)$ & $12,058(9.0)$ & $1,<0.001$ \\
\hline Bipolar Disorder & $241(6.0)$ & $1,678(1.3)$ & $1,<0.001$ \\
\hline Generalized Anxiety Disorder & $345(8.5)$ & $1,994(1.5)$ & $1,<0.001$ \\
\hline
\end{tabular}




\begin{tabular}{|c|c|c|c|}
\hline Panic Disorder & $104(2.6)$ & $471(0.4)$ & $1,<0.001$ \\
\hline Phobic Disorder & $67(1.7)$ & $221(0.2)$ & $1,<0.001$ \\
\hline Drug Abuse/Dependence, n (\%) & $246(6.1)$ & $1,097(0.8)$ & $1,<0.001$ \\
\hline Alcohol Abuse/Dependence, n (\%) & $552(13.7)$ & $4,384(3.3)$ & $1,<0.001$ \\
\hline Tobacco Dependence, n (\%) & $582(14.4)$ & $10,283(7.7)$ & $1,<0.001$ \\
\hline
\end{tabular}


Table 2. Multivariable-Adjusted Models Assessing Late-Life PTSD and Risk of

Cardiovascular Diagnosis among Veterans $(\mathrm{N}=138,341)$

\section{Hazard Ratio $(95 \% \text { CI })^{\mathrm{a}}$}

\begin{tabular}{|c|c|c|c|c|}
\hline PTSD Models & CVD & CHF & MI & PVD \\
\hline Unadjusted & $\begin{array}{c}1.80 * * \\
(1.66-1.95)\end{array}$ & $\begin{array}{c}1.56^{* *} \\
(1.42-1.72)\end{array}$ & $\begin{array}{c}1.82 * * \\
(1.63-2.04)\end{array}$ & $\begin{array}{c}1.60 * * \\
(1.47-1.75)\end{array}$ \\
\hline $\begin{array}{l}\text { Adjusted for } \\
\text { Demographics }\end{array}$ & $\begin{array}{c}1.82 * * \\
(1.68-1.97)\end{array}$ & $\begin{array}{c}1.57 * * \\
(1.43-1.73)\end{array}$ & $\begin{array}{c}1.82 * * \\
(1.63-2.05)\end{array}$ & $\begin{array}{c}1.61 * * \\
(1.47-1.76)\end{array}$ \\
\hline $\begin{array}{l}\text { Adjusted for Medical } \\
\text { Comorbidities }^{c}\end{array}$ & $\begin{array}{c}1.75^{* *} \\
(1.61-1.89)\end{array}$ & $\begin{array}{c}1.47 * * \\
(1.33-1.61)\end{array}$ & $\begin{array}{c}1.76 * * \\
(1.57-1.97)\end{array}$ & $\begin{array}{c}1.55^{* *} \\
(1.42-1.70)\end{array}$ \\
\hline $\begin{array}{l}\text { Adjusted for } \\
\text { Substance Use } \\
\text { Disorders }^{\mathrm{d}}\end{array}$ & $\begin{array}{c}1.69 * * \\
(1.56-1.83)\end{array}$ & $\begin{array}{c}1.45^{* *} \\
(1.32-1.59)\end{array}$ & $\begin{array}{c}1.71 * * \\
(1.53-1.92)\end{array}$ & $\begin{array}{c}1.48 * * \\
(1.36-1.63)\end{array}$ \\
\hline $\begin{array}{l}\text { Adjusted for } \\
\text { Psychiatric } \\
\text { Disorders }\end{array}$ & $\begin{array}{c}1.50 * * \\
(1.38-1.63)\end{array}$ & $\begin{array}{c}1.35^{* *} \\
(1.23-1.49)\end{array}$ & $\begin{array}{c}1.56 * * \\
(1.39-1.76)\end{array}$ & $\begin{array}{c}1.41 * * \\
(1.28-1.54)\end{array}$ \\
\hline Adjusted for All & $\begin{array}{c}1.45^{* *} \\
(1.33-1.58)\end{array}$ & $\begin{array}{c}1.26^{* *} \\
(1.14-1.38)\end{array}$ & $\begin{array}{c}1.49 * * \\
(1.32-1.68)\end{array}$ & $\begin{array}{c}1.35^{* *} \\
(1.23-1.48)\end{array}$ \\
\hline
\end{tabular}

$* P<0.05 ; * * P<0.001$

${ }^{\mathrm{a}}$ Wald chi-square (all DFs $=1$ )

${ }^{\mathrm{b}}$ Demographics $=$ Sex, education, and income

${ }^{\mathrm{c}}$ Medical = Dementia, TBI, renal disease, hypertension, diabetes, cancer, and chronic pulmonary disease

${ }^{\mathrm{d}}$ Substance use disorders = Drug abuse, alcohol abuse, and tobacco dependence

${ }^{\mathrm{e}}$ Psychiatric disorders = Depression, dysthymia, bipolar disorder, GAD, panic disorder, phobic disorder 


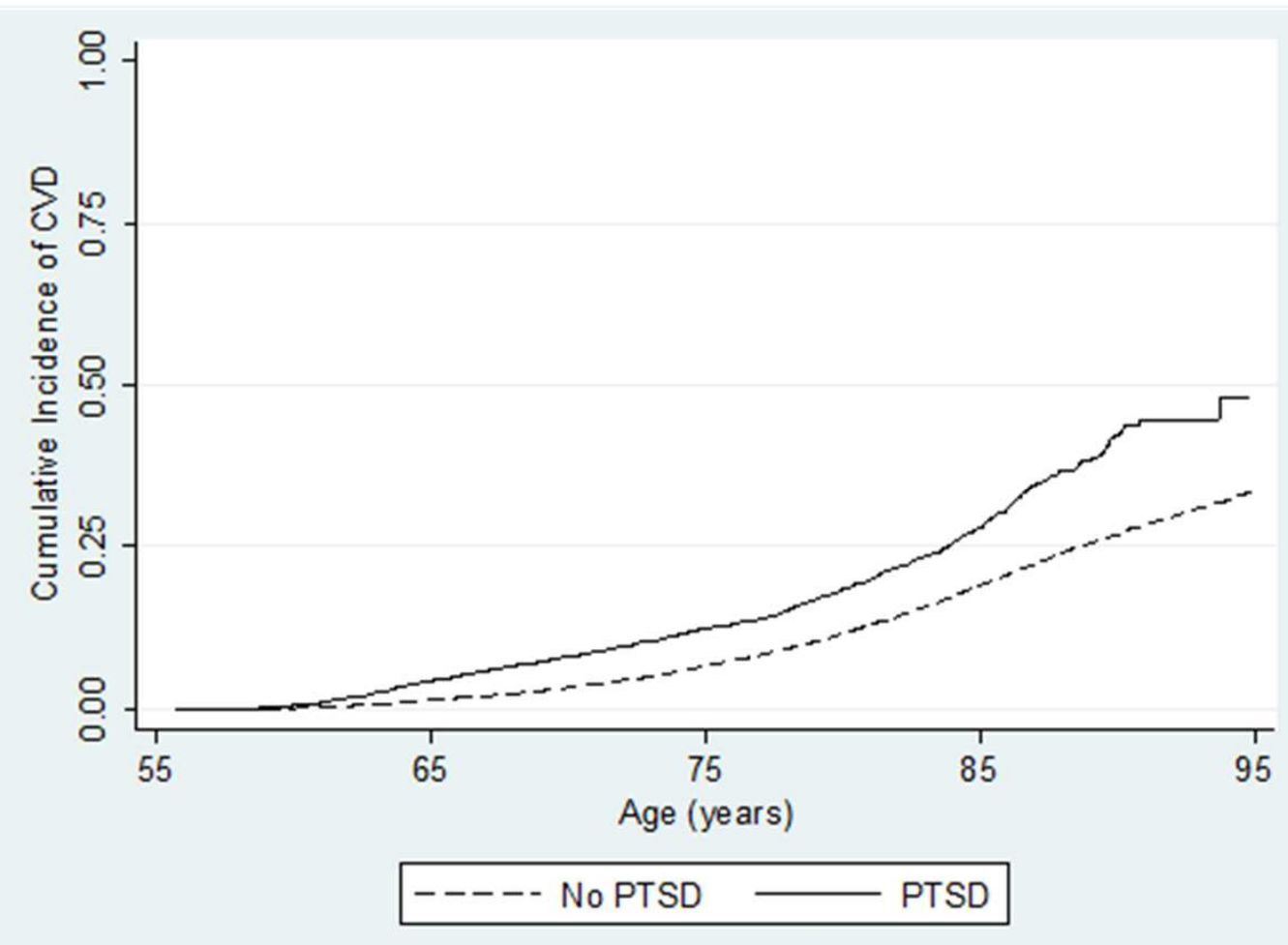




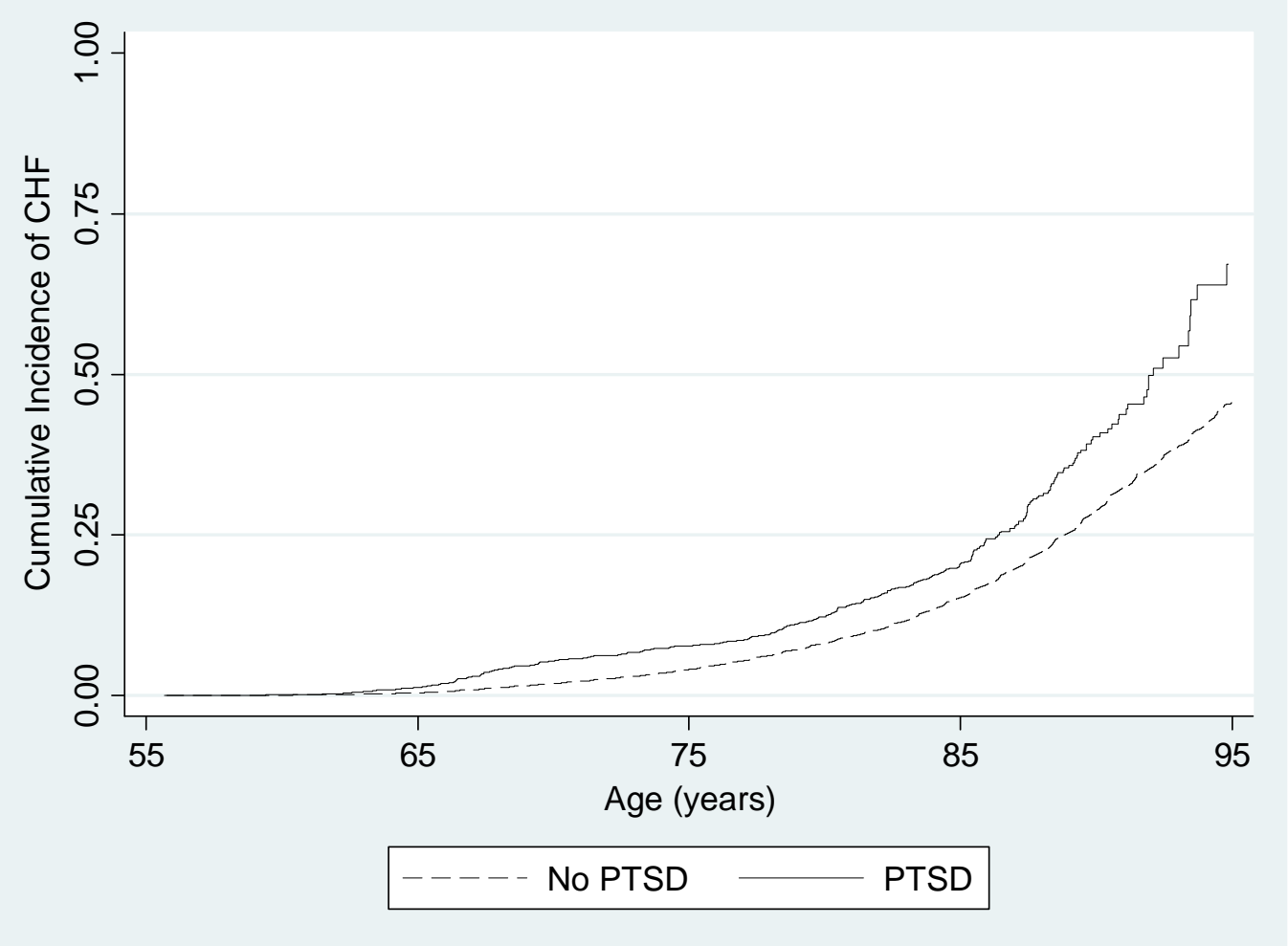




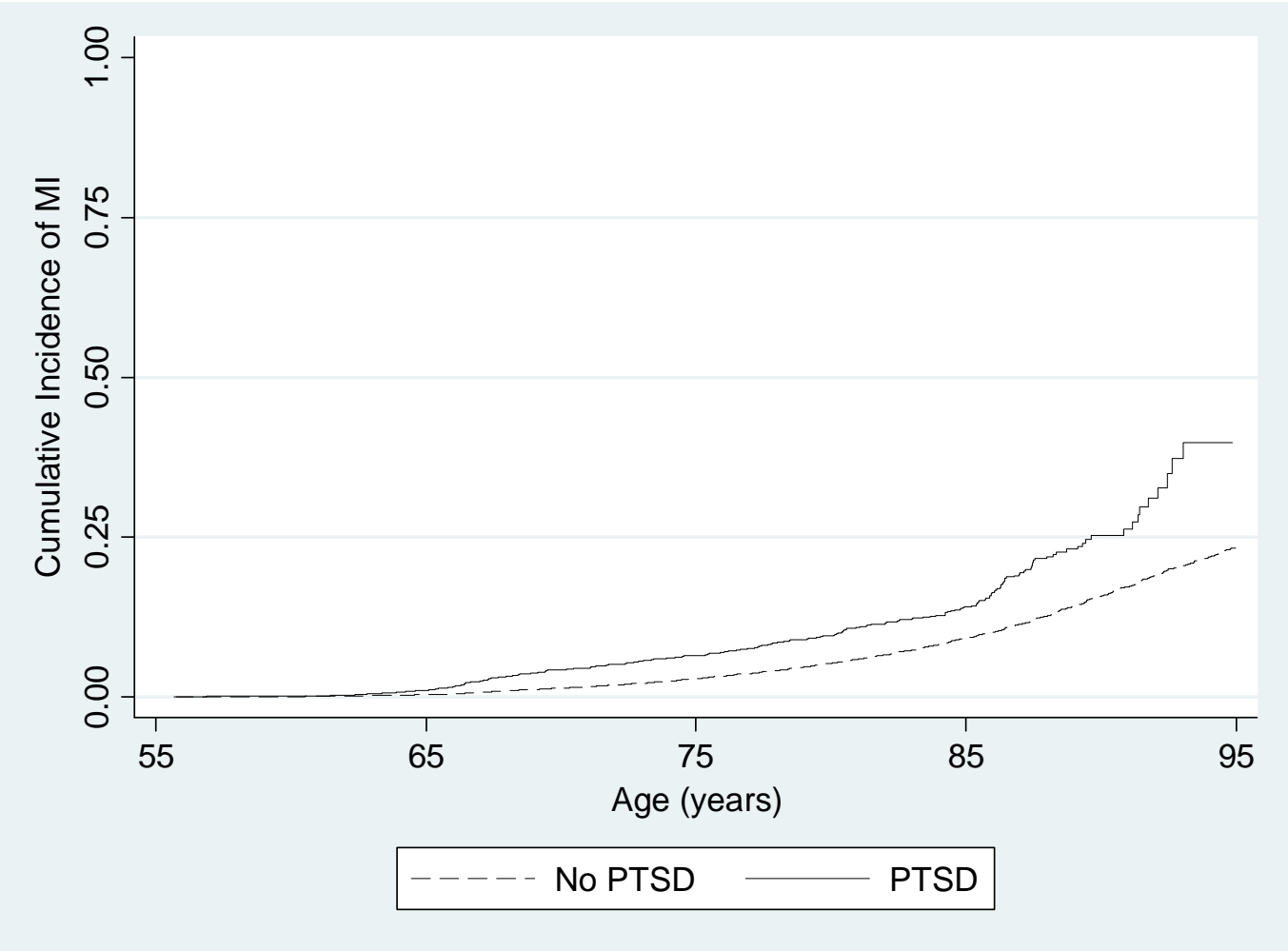




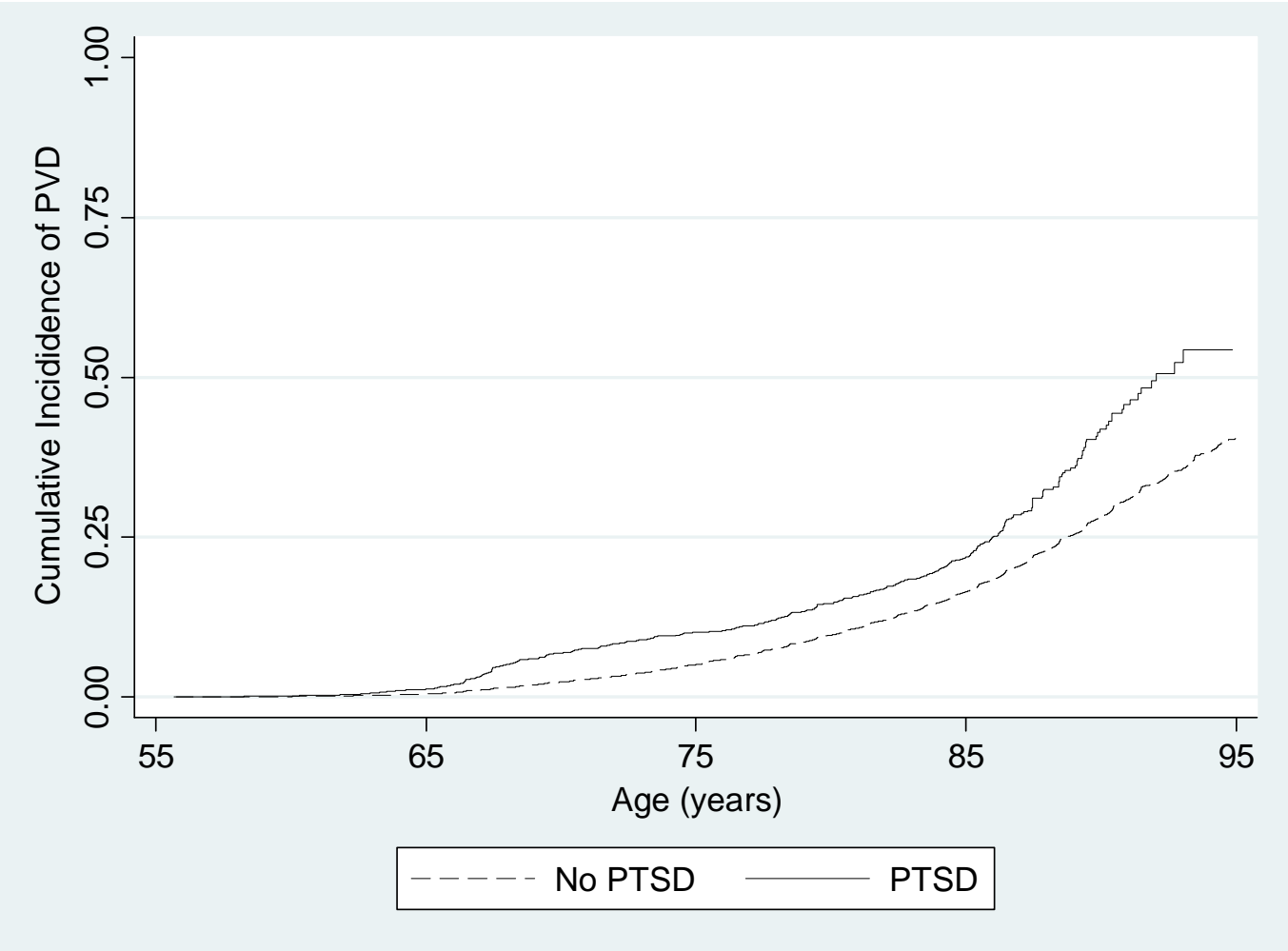

